\title{
Clinical characteristics of patients based on the POL-AF registry compared to the registries of the pre - NOACs era. Do we still treat the same individuals?
}

Janusz Bednarski ${ }^{*}$, Elwira Bakuła-Ostalska ${ }^{1}$, Iwona Gorczyca ${ }^{2}$, Olga Jelonek², Beata Wożakowska-Kapłon², Beata Uziębło-Życzkowska ${ }^{3}$, Małgorzata Maciorowska ${ }^{3}$, Maciej Wójcik ${ }^{4}$, Robert Błaszczyk ${ }^{4}$, Renata Rajtar-Salwa ${ }^{5}$, Tomasz Tokarek ${ }^{5}$, Jacek Bil ${ }^{6}$, Michał Wojewódzki ${ }^{6}$, Anna Szpotowicz ${ }^{7}$, Małgorzata Krzciuk ${ }^{7}$, Monika Gawałko ${ }^{8}$, Agnieszka Kapłon-Cieślicka ${ }^{8}$, Anna Tomaszuk-Kazberuk ${ }^{9}$,Anna Szyszkowska9, Marcin Wełnicki ${ }^{10}$ and Artur Mamcarz ${ }^{10}$

${ }^{1}$ Department of Cardiology, St John Paul II Western Hospital, Clinic of Cardiology, Lazarski University, Grodzisk Mazowiecki, Poland

${ }^{2} 1^{\text {st }}$ Clinic of Cardiology and Electrotherapy, Swietokrzyskie Cardiology Centre, Collegium Medicum, The Jan Kochanowski University, Kielce, Poland

${ }^{3}$ Department of Cardiology and Internal Diseases, Military Institute of Medicine, Warsaw, Poland

${ }^{4}$ Department of Cardiology, Medical University of Lublin, Lublin, Poland

${ }^{5}$ Department of Cardiology and Cardiovascular Interventions, University Hospital, Krakow, Poland

${ }^{6}$ Department of Invasive Cardiology, Centre of Postgraduate Medical Education, Warsaw, Poland

${ }^{7}$ Department of Cardiology, Ostrowiec Swiętokrzyski, Poland

${ }^{8} 1^{\text {st }}$ Department of Cardiology, Medical University of Warsaw, Warsaw, Poland

${ }^{9}$ Department of Cardiology, Medical University of Bialystok, Bialystok, Poland

${ }^{10} 3^{\text {rd }}$ Department of Internal Diseases and Cardiology, Warsaw Medical University, Poland

\begin{abstract}
Background: Atrial fibrillation (AF) is the most common arrhythmia in adults and the most common arrhythmia requiring hospitalization. This paper, taking into account the latest Polish POL-AF registry results, attempts to answer whether and how currently hospitalized patients with AF differ in clinical profile from patients a decade ago and earlier.
\end{abstract}

Methods: The Polish Atrial Fibrillation (POL-AF) Registry is a multicenter, prospective, observational study including hospitalized patients with AF in ten cardiology centers in 2019.

Results: During the study period, 3,999 patients with AF were included in the POL-AF registry. The average age of patients enrolled was 72,1 years, with 42,6\% female. The most prevalent concomitant conditions were arterial hypertension $(83,6 \%)$ and chronic heart failure $(65,5 \%)$. Other comorbidities commonly present were coronary artery disease (50\%), valvular heart disease (37\%) and diabetes mellitus (34,1\%). The history of a previous stroke/TIA was reported in $17,4 \%$ of the patients. The mean CHA2DS2-VASc score and HAS-BLED score were 4,35 and 2,69, respectively.

Conclusion: The POL-AF Registry is the newest and largest multicenter registry on AF in hospitalized patients in Poland and one of the most up-to-date registries of this type in Europe. Compared to years before the NOACs era, we currently treat increasingly younger AF patients, who are burdened with a growing number of comorbidities in particular hypertension, heart failure, vascular diseases, chronic kidney disease, thyroid diseases, previous stroke, diabetes and obesity.

What's new?

Based on the data from the newest and the most significant multicenter study concerning Polish hospitalized patients with atrial fibrillation we can state that presentday patients compared to ones before the NOACs era, are younger, burdened with a growing number of comorbidities in particular hypertension, heart failure, vascular diseases, chronic kidney disease, thyroid diseases, previous stroke, diabetes and obesity. The results can be related to a vast community of atrial fibrillation patients worldwide.

Abbreviation: AFFIRM: The Atrial Fibrillation Follow-up Investiga-
tion of Rhythm Management Study; EHS: Euro Heart Survey; FRACTAL:
The Fibrillation Registry Assessing Costs Therapies, Adverse events and
Lifestyle; ATRIA: Anticoagulation and Risk Factors in Atrial Fibrillation;
SNP: Swedish National Patient Register; US Market: the US Market Scan
database; AFNET: The German Competence NETwork on Atrial Fibril-
lation; RECORD AF: Registry on Cardiac Rhythm Disorders Assess-
ing the Control of Atrial Fibrillation; WHR: Western Hospital Registry
${ }^{*}$ Correspondence to: Bednarski J, MD, PhD, Department of Cardiology, St John Paul II Western Hospital, Clinic of Cardiology, Lazarski University, Daleka 11, 08-825 Grodzisk Mazowiecki, Poland, Tel: +48 22 7559025; Fax: +48 22 7559024; E-mail: medbed@wp.pl

keywords: atrial fibrillation, hospital registry, baseline characteristics

Received: June 19, 2021; Accepted: July 06, 2021; Published: July 09, 2021 


\section{Introduction}

Atrial fibrillation is the most common arrhythmia in adults regardless of the world's region and the most common arrhythmia requiring hospitalization $[1,2]$. The morbidity is a cardiovascular pandemic, affecting more than 33 million people around the globe. Each year, we record over 5 million new cases of AF [3]. This situation carries enormous social and economic costs, which is a great challenge for healthcare systems, regardless of how they are organized and financed.

Currently, the estimated prevalence of AF in the general population is $2-4 \%$ [1], which is at least twice the rate estimated twenty years ago. The lifetime risk of AF in a person aged 55 is currently as high as $37 \%[4,5]$. The increase in the prevalence of AF can be attributed both to better detection of clinically silent $\mathrm{AF}$ as well as the population ageing and the increase in the prevalence of AF-favorable conditions. The incidence of AF is almost 3.5 times higher among men, especially of the Caucasian race, compared to women. Approximately $70 \%$ of AF patients are over 70 years [3]. Age is an essential AF risk factor. Other important risk factors of AF are hypertension, diabetes, heart failure, coronary heart disease, chronic renal failure, obesity and obstructive sleep apnea [6].

Looking from the perspective of clinical practice in the last 20 years, one cannot help feeling that AF patients' profile has changed significantly in favor of people considerably younger, potentially healthier, less burdened with comorbidities than in the previous decade. While at the beginning of the 21st-century patients with AF under 50 were extremely rare, in 2020 , such patients are commonplace in our clinical practice. The number of people aged 50-60 with first $\mathrm{AF}$ episodes is also growing. We observe a continuous increase in the number of AF-related hospitalizations. The highest increase concerns the age group 35-49 years (about 17\%), slightly fewer patients $>80$ years of age (about 15\%) and patients aged 50-64 (about 10\%) [2]. Are these observations and data from population studies supported by the latest AF registry studies? Do we treat the same patients in the non-vitamin $\mathrm{K}$ antagonist oral anticoagulants (NOAC) era as in the time of vitamin $-\mathrm{K}$ antagonists (VKA) and aspirin only? This paper, considers the results of the latest Polish POL-AF registry attempts to answer these questions.

\section{Methods}

\section{Study group}

The Polish Atrial Fibrillation (POL-AF) registry is a multicenter, prospective, observational study that includes patients with AF from ten independent cardiology centers with different reference levels. The data was collected from January to December 2019. The registry aimed to obtain the data concerning detailed baseline clinical characteristics of all AF patients and to evaluate the studied population in terms of upstream therapy and anticoagulation treatment. Consecutive patients over 18 years of age, with AF confirmed with electrocardiographic examination or documented in medical records, admitted electively or urgently to cardiology centers, were added to the survey. No exclusion criteria were defined to avoid a biased selection of patients and get results as close to "real life" as possible. In the presented study based on the POL-AF registry, baseline characteristics of the studied population were evaluated.

To compare the POL-AF registry data with the data from the registries before 2010, we searched PubMed databases and selected ten registries from years 1995-2010 assesing similar demographic and clinical variables as our survey.

\section{Analyzed data}

Critical data connected with demography, medical history, AF type, laboratory tests, and pharmacotherapy were collected independently in each center participating in the study. The thromboembolic risk was estimated based on CHA2DS2-VASc score (congestive heart failure, hypertension, age $\geq 75$ years, diabetes, stroke/transient ischemic attack, vascular disease ( prior myocardial infarction, peripheral artery disease, or aortic plaque ), age 65-74 years, sex) [6]. Bleeding risk was assessed according to HAS-BLED (Hypertension, Abnormal renal/ liver function, Stroke, Bleeding, Labile INR, Elderly ( $>65$ years), Drug/ Alcohol consumption) [6].

Laboratory tests included blood chemistry evaluating predominantly renal and liver function, as well as morphology parameters. Estimated glomerular filtration rate (eGFR) was calculated from the Modification of Diet in Renal Disease or Chronic Kidney Disease Epidemiology Collaboration formula. BMIs were calculated based on patients' height and weight. The available echocardiography results were analyzed for systolic and diastolic function and valve disorders. The local Ethics Committee approved the study protocol and waived the requirement of obtaining informed consent from the patients to participate in the study. The study is registered in the Clinical Trials database -NCT04419012.

\section{Statistical analysis}

The statistical analysis was performed using RStudio Desktop 1.3.1093 (open-source statistical software). Continuous variables were presented as means and categorical variables as absolute and relative frequencies (percentages). Age is the only continuous feature. The statistical test aiming at measuring the significance of occurence of a feature between two samples is the test for proportions (prop. test in RStudio). The prop. test performs a two-sample test for proportions and gives a confidence interval for the difference in proportions as part of the output. In addition, it calculates p-value from the chi-square test. For the two-sample situation, the test takes as arguments values representing the number of events in each of the two groups and values representing the number of subjects in each of the two groups. To test the null hypothesis of no difference between the two proportions, the two-tailed p-value test is used with a conventional alpha level of 0.05 . Results, where p-value was less than the significance level, were considered significant.

\section{Results}

During the study period, 3,999 patients with AF were included in the POL-AF registry. Their baseline characteristics are detailed in Table 1.

The mean age was 72,1 years. Women constituted $42,6 \%$ of the cohort. At the time of enrolment into the registry, $48 \%$ presented with paroxysmal AF, $23,3 \%$ with persistent, $28,6 \%$ with permanent. Atrial flutter was reported in approximately $9 \%$ of patients. The most prevalent concomitant conditions were arterial hypertension $(83,6 \%)$ and chronic heart failure $(65,5 \%)$. Other comorbidities commonly present were coronary artery disease (50\%),valvular heart disease (37\%) and diabetes mellitus $(34,1 \%)$. Active smoking was observed in $11,2 \%$ of patients. The high proportion of patients with valvular heart disease was mostly due to a high prevalence of mitral valve regurgitation, which was reported to be present in $25 \%$ of all patients. Non-cardiac diseases frequently present were renal failure $(30,2 \%)$, thyroid disease $(18,2 \%)$ and chronic obstructive pulmonary disease $(8,8 \%)$. Previous thromboembolic events were common and present with a frequency of $13,0 \%$. The history of a previous stroke/TIA was found in $17,4 \%$ of 
Bednarski J (2021) Clinical characteristics of patients based on the POL-AF registry compared to the registries of the pre - NOACs era. Do we still treat the same individuals?

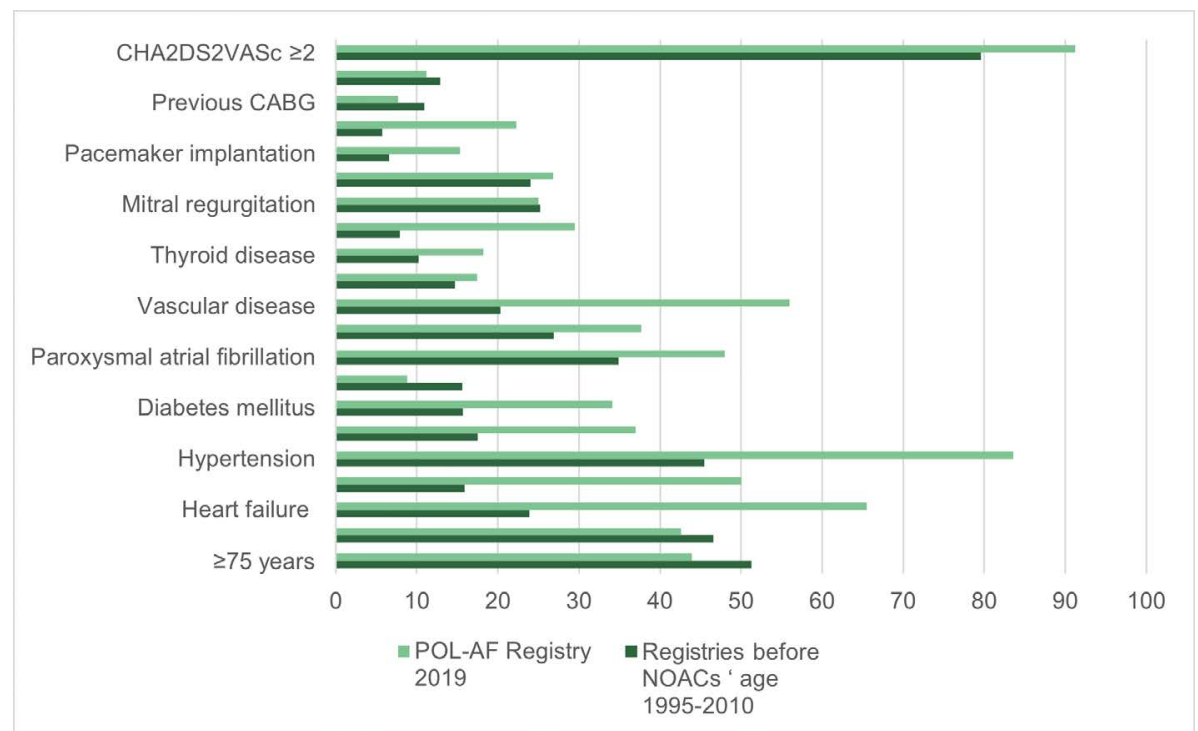

Figure 1. Comparison of pivotal pre -NOACs era registries with the POL-AF Registry BMI- body mass index, EF-ejection fraction, TIA- transient ischemic attack, CABG-coronary artery bypass grafting, $\mathrm{CHA}_{2} \mathrm{DS}_{2} \mathrm{VASc} \geq 2$ (congestive heart failure, hypertension, age $\geq 75$ years, diabetes mellitus, stroke/transient ischemic attack, vascular disease, age $65-74$ years, sex category)

Table 1. Baseline characteristics of the POL-AF Registry patients; Continuous variables are reported as median, categorical variables as number (percentage).

\begin{tabular}{|c|c|}
\hline All patients $\mathrm{n}(\%)$ & $3999(100)$ \\
\hline Mean age, years (SD) & $72,1(11,4)$ \\
\hline Female gender & $1704(42,6)$ \\
\hline Heart failure & $2621(65,5)$ \\
\hline Coronary artery disease & $2011(50,0)$ \\
\hline PAD & $582(14,5)$ \\
\hline Hypertension & $3344(83,6)$ \\
\hline Valvular heart disease & $1497(37,0)$ \\
\hline Diabetes mellitus & $1366(34,1)$ \\
\hline Chronic obstructive pulmonary disease & $354(8,8)$ \\
\hline Paroxysmal atrial fibrillation & $1923(48,0)$ \\
\hline $\mathrm{EF}<50 \%$ & $1179(29,4)$ \\
\hline VAS-vascular disease & $2243(56,0)$ \\
\hline Stroke & $508(12,7)$ \\
\hline TIA & $190(4,7)$ \\
\hline Thyroid disease & $730(18,2)$ \\
\hline Hypothyroidism & $450(11,2)$ \\
\hline Chronic kidney disease & $1029(25,7)$ \\
\hline Mitral regurgitation & $960(25,0)$ \\
\hline BMI $>30$ & $1073(26,8)$ \\
\hline ICD/CRT & $295(7,3)$ \\
\hline Pacemaker implantation & $614(15,3)$ \\
\hline Previous myocardial infarction & $894(22,3)$ \\
\hline Previous CABG & $311(7,7)$ \\
\hline Current smoker & $411(11,2)$ \\
\hline PCI-percutaneus coronary intervention & $918(22,9)$ \\
\hline History of gastrointestinal bleeding & $155(3,9)$ \\
\hline $\mathrm{CHA}_{2} \mathrm{DS}_{2}$ VASc score $\geq 2$ & $3647(91,2)$ \\
\hline Mean $\mathrm{CHA}_{2} \mathrm{DS}_{2}$ VASc score (SD) & $4,35(1,7)$ \\
\hline Mean HAS-BLED(SD) & $2,69(0,9)$ \\
\hline HAS-BLED $\geq 3$ & $2267(56,7)$ \\
\hline
\end{tabular}

Abbreviations: SD-standard deviation, BMI-body mass index, PAD-Peripheral artery disease, EF-ejection fraction, , $\mathrm{CHA}_{2} \mathrm{DS}_{2} \mathrm{VASc} \geq 2$ (congestive heart failure, hypertension, age $\geq 75$ years, diabetes mellitus, stroke/transient ischemic attack, vascular disease, age 65 74 years, sex category), HAS-BLED (Hypertension, Abnormal renal/liver function, Stroke, Bleeding, Labile INR, Elderly $>65$ years, Drug/Alcohol consumption), ICD- implantable cardioverter defibrillator, CRT- cardiac resynchronization therapy, TIA- transient ischemic attack, CABG-coronary artery bypass grafting patients. The mean CHA2DS2-VASc score and HAS-BLED score were 4,35 and 2,69 , respectively. Over $91 \%$ of patients had a high risk of stroke $\left(\mathrm{CHA}_{2} \mathrm{DS}_{2}\right.$-VASc score $\geq 2$ ). Only $2,3 \%$ of patients were reported to have 0 points in the CHA2DS2-VASc score. $56,7 \%$ of the studied patients had a high risk of bleeding. The average BMI was $29,2 \mathrm{~kg} / \mathrm{m} 2$. Obesity with BMI $>30$ was noticed in $26,8 \%$.

$22,6 \%$ patients of the studied cohort had a history of cardiac device implantation twice more frequently pacemakers $(15,3 \%)$ than Implantable Cardioverter-Defibrillators (ICD) or cardiac resynchronization therapy (CRT) device (7,3\%).

To answer the central question of this paper, we summarized the data on patients' clinical characteristics from the available large European and American registries kept in 1995-2008 as well as from two smaller Polish registries from 2006-2010 [7-18]-details in Figure 1 and Table 2.

The registries that were considered for comparison with the POL-AF registry and the patients' clinical characteristics are presented in Table 3.

Compared to the patients treated before NOACs age, present-day patients with AF are younger 72,1 versus 74,4 years, with a smaller number of patients over 75 years: $43,9 \%$ versus 51,3\% but with a significantly greater number of patients at high risk of thromboembolic events $(91,2 \%$ and $79,6 \%$, respectively; all P- values $<0,001)$. Nowadays, women constitute a smaller group of patients with AF than before: (42,6\% and 46,6\%, accordingly; P-value $<0,001$ ).

Both hypertension and coronary artery disease, as well as heart failure, valvular disease and vascular disease, were more commonly reported in present-day patients with $\mathrm{AF}$ (all P-values $<0.001$ ).

Conversely, active smoking, chronic obstructive pulmonary disease, and previous $\mathrm{CABG}$ were more likely to have occurred in AF patients a decade ago and earlier ( $\mathrm{P}$-value $<0,001)$.

Paroxysmal AF was more prevalent in the POL-AF registry than in the period before 2010 ( $48 \%$ and $34,9 \%$, respectively; P-value $<0,001$ ).

Among concomitant risk factors, diabetes was more than twice likely to be reported in present-day patients with $\mathrm{AF}(34,1 \%$ and $15,7 \%$, respectively; P-value $<0,001$ ). 
Bednarski J (2021) Clinical characteristics of patients based on the POL-AF registry compared to the registries of the pre - NOACs era. Do we still treat the same individuals?

Table 2. Comparison of registries before 2010 with the POL-AF Registry

\begin{tabular}{|c|c|c|c|}
\hline \multirow{3}{*}{ Characteristics } & Registries before & POL-AF Registry & \multirow{3}{*}{ P-value } \\
\hline & NOACs'age & 2019 & \\
\hline & $1995-2010$ & & \\
\hline All patients & 477437 & 3999 & - \\
\hline Mean age, years & 74,4 & 72,1 & - \\
\hline$\geq 75$ years & $69752 / 136065(51,3)$ & $1757 / 3999(43,9)$ & $<0,001$ \\
\hline Female gender & $222857 / 477437(46,6)$ & $1704 / 3999(42,6)$ & $<0,001$ \\
\hline Heart failure & $114140 / 477437(23,9)$ & $2621 / 3999(65,5)$ & $<0,001$ \\
\hline Coronary artery disease & $53793 / 337017(15,9)$ & $2011 / 3999(50,0)$ & $<0,001$ \\
\hline Hypertension & $217225 / 477437(45,5)$ & $3344 / 3999(83,6)$ & $<0,001$ \\
\hline Valvular heart disease & $7767 / 44344(17,5)$ & $1497 / 3999(37,0)$ & $<0,001$ \\
\hline Diabetes mellitus & $74962 / 477437(15,7)$ & $1366 / 3999(34,1)$ & $<0,001$ \\
\hline Chronic obstructive pulmonary disease & $29845 / 190851(15,6)$ & $354 / 3999(8,8)$ & $<0,001$ \\
\hline Paroxysmal atrial fibrillation & $8859 / 25365(34,9)$ & $1923 / 3999(48,0)$ & $<0,001$ \\
\hline$E F<50 \%$ & $2267 / 8432(26,9)$ & $1179 / 3123(37,7)$ & $<0,001$ \\
\hline Vascular disease & $53159 / 261700(20,3)$ & $2243 / 3999(56,0)$ & $<0,001$ \\
\hline Stroke/TIA & $70087 / 477437(14,7)$ & $698 / 3999(17,4)$ & $<0,001$ \\
\hline Thyroid disease & $20087 / 196758(10,2)$ & $730 / 3999(18,2)$ & $<0,001$ \\
\hline Chronic kidney disease & $2003 / 25365(7,9)$ & $1029 / 3999(25,7)$ & $<0,001$ \\
\hline Mitral regurgitation & $3435 / 13642(25,2)$ & $960 / 3999(25,0)$ & 0,136 \\
\hline$B M I>30$ & $2223 / 9263(24,0)$ & $1073 / 3999(26,8)$ & $<0,001$ \\
\hline Pacemaker implantation & $378 / 5678(6,6)$ & $614 / 3999(15,3)$ & $<0,001$ \\
\hline Myocardial infarction & $11668 / 204847(5,7)$ & $894 / 3999(22,3)$ & $<0,001$ \\
\hline Previous $\mathrm{CABG}$ & $528 / 4673(10,9)$ & $311 / 3999(7,7)$ & $<0,001$ \\
\hline Current smoker & $1961 / 15170(12,9)$ & $411 / 3999(11,2)$ & $<0,001$ \\
\hline $\mathrm{CHA}_{2} \mathrm{DS}_{2} \mathrm{VASc} \geq 2$ & $105729 / 121280(79,6)$ & $3647 / 3999(91,2)$ & $<0,001$ \\
\hline
\end{tabular}

Abbreviations: BMI- body mass index, EF-ejection fraction, TIA- transient ischemic attack, CABG-coronary artery bypass grafting, $\mathrm{CHA}_{2} \mathrm{DS}_{2} \mathrm{VASc}_{2} \geq 2$ (congestive heart failure, hypertension, age $\geq 75$ years, diabetes mellitus, stroke/transient ischemic attack, vascular disease, age 65-74 years, sex category)

Table 3. Comparison of registries in years 1995-2010

\begin{tabular}{|c|c|c|c|c|c|c|c|c|c|c|c|}
\hline \multirow[t]{2}{*}{ Characteristics } & $\begin{array}{c}\text { AFFIRM } \\
\text { study }\end{array}$ & $\begin{array}{c}\text { Danish } \\
\text { Study }\end{array}$ & EHS & $\begin{array}{c}\text { FRACTAL } \\
\text { Study }\end{array}$ & $\begin{array}{l}\text { ATRIA } \\
\text { Study }\end{array}$ & $\begin{array}{c}\text { SNP } \\
\text { Registry }\end{array}$ & $\underset{\text { Market }}{U S}$ & AFNET & $\begin{array}{c}\text { RECORD } \\
-A F\end{array}$ & WHR & $\begin{array}{c}\text { RECORD } \\
\text { AF-POL }\end{array}$ \\
\hline & 1995-1999 & $1997-2006$ & $2003-2004$ & 1997 & 1996-1997 & $2005-2010$ & $2003-2007$ & $2004-2006$ & $2007-2008$ & $2006-2010$ & 2007 \\
\hline All patients & 4060 & 121280 & 5333 & 1005 & 17974 & 140420 & 171393 & 9582 & 5604 & 613 & 303 \\
\hline Mean age & 69,7 & NA & 66,7 & 65,9 & 71,2 & 77,2 & 73,5 & 68,4 & 66,0 & 74,8 & 63,0 \\
\hline Age $\geq 75$ years & NA & 54,0 & 27,7 & NA & NA & NA & NA & 29,2 & NA & NA & NA \\
\hline Female gender & 39,0 & 46,6 & 42 & 39,6 & 43,4 & 50,1 & 45,2 & 38,9 & 42,8 & 51,2 & 42,6 \\
\hline$H F$ & 23,0 & 18,8 & 33,6 & 18,2 & 29,2 & 31,9 & 19,7 & 29 & 25,9 & 61,7 & 27,8 \\
\hline$C A D$ & 38,0 & 16,7 & 32,7 & 24,6 & 34,6 & NA & 11,6 & 28,1 & 18,0 & 43,1 & 18,9 \\
\hline Hypertension & 71,0 & 39,7 & 63,7 & 48,8 & 49,3 & 43,8 & 47,2 & 69,2 & 68,0 & 65,9 & 71,5 \\
\hline VHD & 12,0 & NA & 26,3 & 17,3 & 4,9 & NA & NA & 36,3 & 19,3 & 36,4 & 22,7 \\
\hline$D M$ & 20,0 & 9,1 & 18 & 11,8 & 17,1 & 16,4 & 19,1 & 21,7 & 15,7 & 25,4 & 12,3 \\
\hline COPD & 15,0 & NA & 13,3 & NA & NA & NA & 16 & 11,4 & NA & 17,3 & NA \\
\hline$P A F$ & 31,0 & NA & 29 & NA & NA & NA & NA & 30,2 & 52,3 & 43,3 & 57,9 \\
\hline$E F<50 \%$ & 32,0 & NA & NA & NA & NA & NA & NA & NA & 22,0 & NA & NA \\
\hline Vascular disease & NA & 16,7 & NA & NA & NA & 23,4 & NA & NA & NA & NA & NA \\
\hline Stroke/TIA & 13,0 & NA & $5,5 / 5$ & 7,4 & 8,9 & $15,2 / 5,7$ & 7,5 & $6,4 / 3,5$ & $5,7 / 4$ & 16,5 & $2,7 / 2,3$ \\
\hline Thyroid disease & 12,0 & NA & 9,4 & NA & NA & NA & 10.1 & 12,1 & 9,0 & 12,0 & 4,4 \\
\hline Renal failure & 1.8 & NA & 5,8 & NA & NA & NA & NA & 11,6 & 6,0 & 27,7 & 5,3 \\
\hline Mitral regurgitation & 20,0 & NA & NA & NA & NA & NA & NA & 29,1 & NA & NA & NA \\
\hline$B M I>30$ & 21,9 & NA & 25,0 & NA & NA & NA & NA & NA & NA & NA & NA \\
\hline MI & 17,0 & NA & 14,5 & NA & 9.4 & NA & 4,6 & NA & 9,0 & 23,8 & NA \\
\hline Current smoker & 14,0 & NA & NA & NA & NA & NA & NA & NA & 13,0 & NA & 14,6 \\
\hline $\mathrm{CHA}_{2} \mathrm{DS}_{2} \mathrm{VASc} \geq 2$ & NA & 79,6 & NA & NA & NA & NA & NA & NA & NA & NA & NA \\
\hline$B M I$ & 29,0 & NA & 28,0 & NA & NA & NA & NA & 27,7 & 28,4 & NA & NA \\
\hline
\end{tabular}

Abbreviations: NA-not available, COPD-Chronic obstructive pulmonary disease, PAF-Paroxysmal atrial fibrillation, HF- heart failure, CAD-Coronary artery disease, BMI- body mass index, VHD- Valvular heart disease, DM- Diabetes mellitus, MI- Myocardial infarction, $\mathrm{CHA}_{2} \mathrm{DS}_{2}$ VASc $\geq 2$ (congestive heart failure, hypertension, age $\geq 75$ years, diabetes mellitus, stroke/ transient ischemic attack, vascular disease, age 65-74 years, sex category) 
In $2019 \mathrm{AF}$ patients had more prevalent non-cardiac comorbidities, such as thyroid disease, previous stroke / TIA, obesity, and chronic kidney disease (all P-values $<0,001$ ).

\section{Discussion}

The POL-AF registry is one of the most recent and up-to-date registries in Europe concerning the clinical characteristics of $\mathrm{AF}$ patients and their treatment.

Contrary to randomized clinical trials (RCTs), clinical registries on AF can better describe the real-life population and contemporary clinical practice than RCTs.

As mentioned in the introduction, AF now occurs in increasingly younger people which was confirmed in the presented registry with an average age of 72.1 years and proves consistent with data from other registries kept in the last few years. Examples include the Japanese registries: RAFFINE [19] with an average age of 72.6 and SAKURA AF [20] - 72.0, the international registry GARFIELD-AF [21] with an average age of 69.7 years and GLORIA-AF [22] - 71 years, as well as the European EORP-AF registry [23] with the mean age of 71 years. The increase in the percentage of young patients with AF requiring hospitalization, especially those between $35-49$ years of age, was already noticed at the end of the first decade of the 21st century, just before the NOACs era [2]. Most of the currently hospitalized AF patients in Poland are under 75 years old. A similar fact was also ascertained in the GARFIELD-AF registry where patients in this age group figured more than $60 \%$ [24].

Since 2000, a gradual decrease in hospitalization has been observed in women compared to men. While 20 years ago, the percentage of hospitalization among women with AF was even 55\% [2], it is now just above $40 \%$. The proportion of women in the presented study was $42.6 \%$ and remains at a similar level to other contemporary observational studies such as GARFIELD-AF (44. 2\%), PREFER AF (40.0\%) [25], EORP-AF (40. 4\%) or CRAFT (40.2\%) [26].

Heart failure and atrial fibrillation are two common cardiovascular disorders that often complicate one another. In the studied population, heart failure at discharge was diagnosed in over $65 \%$ of patients, i.e. about three times more often than in most pre-2010 observational studies such as AFFIRM [8], Euro Heart Survey [9], ATRIA [11], RECORD- AF [15] and AFNET [13], as well as in current registries: GARFIELD-AF, ORBIT AF II [21] and EORP-AF.

One of the main reasons for such large differences in HF prevalence in the studied populations is the choice of centers participating in observational studies: large metropolitan university hospitals participating in RCTs and international registers versus smaller tertiary and district hospitals.

To the POL-AF study some secondary hospitals were invited which, due to the specific geographical location and nature of their activity, treat less selected patients, paradoxically more burdened with comorbidities than patients in centers of the highest reference.

Another reason may be that the POL-AF registry applies only to hospitalized patients, which defines the studied population as higher cardiovascular risk than the outpatient one. Multicenter hospital-only surveys are rare. An example is the GLORIA-AF registry kept in 20112014. In the European cohort of that study, HF patients amounted to $23.4 \%$, which is almost three times less than in Poland today.

$\mathrm{CHA}_{2} \mathrm{DS}_{2}-\mathrm{VASc} \geq 2$ and HAS-BLED $\geq 3$ are recognized markers of high complications risk.
In the studied population, the average number of points on the $\mathrm{CHA}_{2} \mathrm{DS}_{2}$-VASc score was 4.35 compared to 3.0 points in the EHS study, 3.2 points in GLORIA-AF and GARFIELD AF, 3.9 in ORBIT -AF, 3.24 in EORP AF.

The percentage of patients with $\mathrm{CHA}_{2} \mathrm{DS}_{2}-\mathrm{VASc} \geq 2$ in the studied population was as high as $91.2 \%$ compared to $79.6 \%$ reported in the records ten years ago.

The mean HAS-BLED score in our registry was 2.69. The percentage of patients with high and very high bleeding risk was $56.7 \%$, which is a vast difference compared to $21.3 \%$ in ESH.

The prevalence of CAD in the studied population, estimated at $50 \%$, i.e. over three times more than $10-20$ years ago and almost twice as much as reported by large contemporary registries such as EORP-AF $-29.3 \%$, GARFIELD AF $-19.4 \%$ or ORBIT AF II $26.6 \%$. It seems that the reasons for such large differences are similar to those described for HF.

Hypertension (HT) is considered to be the primary independent risk factor for atrial fibrillation. In our registry, HT was present in almost $84 \%$, compared to $45 \%$ of patients before 2010 . In general, all current European registries report the prevalence of hypertension at about $70-85 \%$, which is higher than two decades ago.

Another parameter evaluated in the POL-AF registry was the coexistence of AF and type 2 diabetes mellitus (T2DM). The latest estimates show a global prevalence of 425 million people with diabetes in 2017, which is expected to rise to 629 million by 2045 [27]. This is fueled by the worldwide rise in the prevalence of obesity and unhealthy behaviors, including poor diet and physical inactivity [28]. Given the high prevalence of $\mathrm{AF}$ and $\mathrm{T} 2 \mathrm{DM}$ in the general population, these conditions' frequent coexistence is not surprising. Up to $20 \%$ of patients with AF had T2DM- before 2010. Currently, in the presented registry, it is already $34 \%$.

The number of people with $\mathrm{BMI}>30$ and AF is also significantly higher now than several years ago. This is interesting given that in our registry obesity was found in almost every third AF patient. The growing number of obese people is also evident in other contemporary registries, such as ORBIT-AF or EORP-Pilot [29].

Vascular diseases such as atherosclerosis, peripheral artery disease, myocardial infarction, aortic plaque are inextricably linked to T2DM and obesity. Their presence in the studied population was found in $56 \%$ compared to $20 \%$ of patients a decade or more ago. The number of AF patients with a history of $\mathrm{MI}$ increased (22.3\% vs $5.7 \%)$, which most likely is related to the new definition of myocardial infarction based on determining of troponins, i.e. much more sensitive markers of myocardial necrosis than the previously used CPK or CKMB.

As mentioned in the introduction, the number of people with AF has been gradually increasing over the last 20-30 years. Atrial fibrillation, especially in the paroxysmal form (PAF), affects younger and younger people. In the studied population, PAF was the most common form of AF (48.0\%), significantly more frequent than before (34.9\%).

An increasing number of hospitalized patients with AF have a history of stroke or TIA. There were $17.4 \%$ of such patients in the study group, compared to $14.7 \%$ in the registries before 2010 . This proportion is consistent with the data from other similar studies conducted in recent years. For example, in the Italian AIFA registry [30] kept in 20132017 in a group of over 700000 patients, the percentage of people after stroke / TIA was $18.3 \%$. 

individuals?

Another critical problem is chronic kidney disease, the percentage of which is now more than four times higher than in the past. In our registry, the criterion used for diagnosis of renal failure was $\mathrm{GFR}<50 \mathrm{ml} /$ $\mathrm{min}$, i.e. one that requires a change in the dosage of some NOACs and which at the same time significantly increases the risk of cardiovascular events and death. In the in-patients RAFFINE registry a few years ago, the proportion of patients with chronic kidney disease was $26.5 \%$ versus $30.2 \%$ in POL-AF, what compared to $1.8 \%$ in the AFFIRM study or $5.8 \%$ in the Euro Heart study Survey makes a huge difference.

It also comes as a big surprise that almost every 5 th patient with $\mathrm{AF}$ in our registry had a thyroid disorder defined as TSH out of range. For comparison, in the EORP-AF registry seven years ago, the percentage of patients with thyroid diseases was about $15 \%$ and in the EHS study 17 years ago only $9.4 \%$.

\section{Conclusion}

In summary, the presented registry is the newest and the most significant multicenter study concerning Polish hospitalized patients with atrial fibrillation and one of the most up-to-date records of this type in Europe. Participation in the study, apart from university hospitals, also district hospitals, gives a more reliable picture of AF patients similar to everyday clinical practice in our country. The results of the registry are broadly consistent with our observations and experiences of the last 20-30 years. We are treating increasingly younger patients with AF, burdened with a growing number of comorbidities, particularly hypertension, heart failure, vascular diseases, chronic kidney disease, thyroid diseases, previous stroke, diabetes and obesity. Taking into account the above conclusions, the essential issue that may limit the AF epidemic seems to be the fight against obesity, leading to the development of T2DM as well as vascular diseases, heart failure and hypertension. Effective obesity reduction should be the overriding goal of the health and preventive policies in the modern world.

Patients' clinical characteristics from the POL-AF registry are analogous to those presented in other contemporary international registries, which allows us to relate our results to a vast community of AF patients worldwide.

\section{Limitation}

The design of the POL-AF Study included only hospitalized patients. Thus, the clinical characteristics of POL-AF patients reflect more coexisting severe diseases and conditions than the general population of patients with atrial fibrillation. Data from ten hospital centers out of approximately nine hundred and fifty in Poland do not reflect the full clinical profile of hospitalized AF patients. We did not include in the registry internal medicine departments where a significant amount of AF patients are hospitalized what also could have had an impact on the survey results.

\section{Acknowledgement}

The POL-AF Registry was initiated on the Scientific Platform of the "Club 30" of the Polish Cardiac Society. The authors thank Bartosz Krzemiński, Piotr Bednarski and Arkadiusz Sokołowski, Anna Michalska-Foryszewska, Paweł Krzesiński, Wiktor Wójcik, Monika Budnik, Katarzyna Karoń, Monika Szewczak for assistance in data collection.

\section{Contribution statement}

- Conception and design: JB, EBO, IG
- Administrative support: JB

- Provision of study materials or patients: JB, EBO, BU-Ż, MM, MW, RB, TT, RR-S, J.B, MW, A.S, MK, ATK, AS, M.W, AM.

- Collection and assembly of data: JB, EBO, IG, OJ, BU-Ż, MM, MW, RB, RR-S, TT, J.B, MW, A.S, MK, MG, AK-C

- Data analysis and interpretation: JB and EBO.

- Manuscript writing: JB

- Final approval of manuscript: All authors

\section{References}

1. Benjamin EJ, Muntner P, Alonso A (2019) American Heart Association Council on Epidemiology and Prevention Statistics Committee and Stroke Statistics Subcommittee. Heart disease and stroke statistics 2019 update: a report from the American Heart Association. Circulation 139: e56e528.

2. Sheikh A, Patel NJ, Nalluri N (2015) Trends in hospitalization for atrial fibrillation: epidemiology, cost, and implications for the future. Prog Cardiovasc Dis 58: 105-116. [Crossref]

3. Chugh SS, Havmoeller R, Narayanan K (2014) Worldwide epidemiology of atria fibrillation: a Global Burden of Disease 2010 study. Circulation 129: 837-847. [Crossref]

4. Heeringa J, van der Kuip DA, Hofman A (2006) Prevalence, incidence and lifetime risk of atrial fibrillation: the Rotterdam Study. Eur Heart J 27: 949-953. [Crossref]

5. Lloyd-Jones DM, Wang TJ, Leip EP, Larson MG (2004) Lifetime risk for development of atrial fibrillation: the Framingham Heart Study. Circulation 110: 1042-1046. [Crossref]

6. Hindricks G, Potpara T, Dagres N (2020) 2020 ESC Guidelines for the diagnosis and management of atrial fibrillation developed in collaboration with the European Association of Cardio-Thoracic Surgery (EACTS). Eur Heart J 1-125. [Crossref]

7. Olesen JB, Lip GY, Hansen ML (2011) Validation of risk stratification schemes for predicting stroke and thromboembolism in patients with atrial fibrillation: nationwide cohort study. BMJ 342: 124. [Crossref]

8. AFFIRM Investigators (2002) Atrial Fibrillation Follow-up Investigation of Rhythm Management. Baseline characteristics of patients with atrial fibrillation: the AFFIRM Study. Am Heart $J$ 143: 991-1001.

9. Nieuwlaat R, Capucci A, Camm AJ (2005) European Heart Survey Investigators. Atrial fibrillation management: a prospective survey in ESC member countries: the Euro Heart Survey on Atrial Fibrillation. Eur Heart J 26: 2422-2434. [Crossref]

10. Reynolds MR, Shah J, Essebag V (2006) Patterns and predictors of warfarin use in patients with new-onset atrial fibrillation from the FRACTAL Registry. Am J Cardiol 97: 538-543. [Crossref]

11. Go AS, Hylek EM, Phillips KA (2001) Prevalence of diagnosed atrial fibrillation in adults: national implications for rhythm management and stroke prevention: the AnTicoagulation and Risk Factors in Atrial Fibrillation (ATRIA) Study. JAMA 285: 2370-2375. [Crossref]

12. Friberg L, Skeppholm M, Terént A (2015) Benefit of anticoagulation unlikely in patients with atrial fibrillation and a CHA2DS2-VASc score of $1 . \mathrm{J} \mathrm{Am} \mathrm{Coll} \mathrm{Cardiol}$ 65: 225-232. [Crossref]

13. Nabauer M, Gerth A, Limbourg T (2009) The Registry of the German Competence NETwork on Atrial Fibrillation: patient characteristics and initial management. Europace 11: 423-434. [Crossref]

14. Zimetbaum PJ, Thosani A, Yu HT, Xiong Y (2010) Are atrial fibrillation patients receiving warfarin in accordance with stroke risk? Am J Med 123: 446-453. [Crossref]

15. Camm AJ, Breithardt G, Crijns H (2011) Real-life observations of clinical outcomes with rhythm- and rate-control therapies for atrial fibrillation RECORDAF (Registry on Cardiac Rhythm Disorders Assessing the Control of Atrial Fibrillation). J Am Coll Cardiol 58: 493-501. [Crossref]

16. Opolski G, Kosior DA, Kurzelewski M (2010) Baseline characteristics of patient from Poland enrolled in the global registry of patients with recently diagnosed atrial fibrillation (RecordAF). Kardiol Pol 68: 546-554. [Crossref]

17. Bednarski J, Cieszewska E, Strzelecki A, Filipiak KJ (2013) Anticoagulant and antiplatelet therapy for stroke prevention in atrial fibrillation patients in the clinical practice of a single district hospital in Poland. Kardiol Pol 71: 1260-1265. [Crossref] 
Bednarski J (2021) Clinical characteristics of patients based on the POL-AF registry compared to the registries of the pre - NOACs era. Do we still treat the same individuals?

18. Lip GY, Al-Khatib SM, Cosio FG (2014) Contemporary management of atrial fibrillation: what can clinical registries tell us about stroke prevention an current therapeutic approaches? J Am Heart Assoc 3: e001179. [Crossref]

19. Miyazaki S, Miyauchi K, Hayashi H (2018) Registry of Japanese patients with atrial fibrillation focused on anticoagulant therapy in the new era: The RAFFINE registry study design and baseline characteristics. $J$ Cardiol 71 :590-596. [Crossref]

20. Okumura Y, Yokoyama K, Matsumoto N (2017) The Sakura Af Registry Investigators. Current use of direct oral anticoagulants for atrial fibrillation in Japan: Findings from the SAKURA AF Registry. J Arrhythm 33: 289-296. [Crossref]

21. Steinberg BA, Gao H, Shrader P (2017) GARFIELD-AF; ORBIT-AF Investigators. International trends in clinical characteristics and oral anticoagulation treatment for patients with atrial fibrillation: Results from the GARFIELD-AF, ORBIT-AF I, and ORBIT-AF II registries. Am Heart J 194: 132-140. [Crossref]

22. Huisman MV, Rothman KJ, Paquette M (2015) GLORIA-AF Investigators. Antithrombotic Treatment Patterns in Patients with Newly Diagnosed Nonvalvular Atrial Fibrillation: The GLORIA-AF Registry, Phase II. Am J Med 128: 13061313. [Crossref]

23. Boriani G, Proietti M, Laroche C (2018) EORP-AF Long-Term General Registry Investigators; Steering Committee (National Coordinators) Contemporary stroke prevention strategies in 11096 European patients with atrial fibrillation: a report from the EURObservational Research Programme on Atrial Fibrillation (EORP-AF) Long-Term General Registry. Europace 20: 747-757. [Crossref]

24. Bassand JP, Accetta G, Al Mahmeed W (2018) GARFIELD-AF Investigators. Risk factors for death, stroke, and bleeding in 28,628 patients from the GARFIELD-AF registry: Rationale for comprehensive management of atrial fibrillation. PLoS One 13: e0191592. [Crossref]

25. Hanon O, Vidal JS, Le Heuzey JY (2017) Oral anticoagulant use in octogenarian European patients with atrial fibrillation: A subanalysis of PREFER in AF. Int J Cardiol 232: 98-104. [Crossref]

26. Bednarski J, Balsam P, Tymińska A (2018) District versus academic hospitals: differences in the clinical characteristics of patients with atrial fibrillation without valvular heart disease treated with oral anticoagulants. Pol Arch Intern Med 128: 274-279. [Crossref]

27. Forouhi NG, Wareham NJ (2019) Epidemiology of diabetes. Medicine 47: 22-27. [Crossref]

28. Groh CA, Faulkner M, Getabecha S (2019) Patient-reported triggers of paroxysmal atrial fibrillation. Heart Rhythm 16: 996-1002. [Crossref]

29. Lip GY, Laroche C, Boriani G (2015) Sex-related differences in presentation, treatment, and outcome of patients with atrial fibrillation in Europe: a report from the Euro Observational Research Programme Pilot survey on Atrial Fibrillation. Europace 17: 24-31. [Crossref]

30. Olimpieri PP, Di Lenarda A, Mammarella F (2020) Non-vitamin K antagonist oral anticoagulation agents in patients with atrial fibrillation: Insights from Italian monitoring registries. Int J Cardiol Heart Vasc 26: 100465. [Crossref]

Copyright: $(02021$ Bednarski J. This is an open-access article distributed under the terms of the Creative Commons Attribution License, which permits unrestricted use, distribution, and reproduction in any medium, provided the original author and source are credited. 